\title{
Accounting for biological and physical sources of acoustic backscatter improves . estimates of zooplankton biomass
}

4 Joseph D. Warren ${ }^{1}$ and Peter H. Wiebe ${ }^{2}$

51 School of Marine and Atmospheric Sciences, Stony Brook University, 239

6 Montauk Hwy, Southampton, New York 11968 USA, joe.warren@stonybrook.edu 7 ph 1-631-632-5045 fax 1-631-632-5070, Corresponding Author.

92 Woods Hole Oceanographic Institution, Woods Hole, Massachusetts 02543

10

USA, pwiebe@whoi.edu 
${ }_{12}$ Abstract: In order to convert measurements of backscattered acoustic en-

13

Keywords: acoustic backscatter, zooplankton, Gulf of Maine becomes a better measure of net-collected zooplankton biomass.

ergy to estimates of abundance and taxonomic information about the zooplankton community, all of the scattering processes in the water column need to be identified and their scattering contributions quantified. Zooplankton populations in the eastern edge of Wilkinson Basin in the Gulf of Maine in the Northwest Atlantic were surveyed in October 1997. Net tow samples at different depths, temperature and salinity profiles, and multiple frequency acoustic backscatter measurements from the upper 200 meters of the water column were collected. Zooplankton samples were identified, enumerated, and measured. Temperature and salinity profiles were used to estimate the amount of turbulent microstructure in the water column. These data sets were used with theoretical acoustic scattering models to calculate the contributions of both biological and physical scatterers to the overall measured scattering level. The output of these predictions shows that the dominant source of acoustic backscatter varies with depth and acoustic frequency in this region. By quantifying the contributions from multiple scattering sources, acoustic backscatter 


\section{Introduction}

Acoustic surveys of zooplankton and fish offer many advantages over other sampling techniques (Holliday and Pieper 1995; Foote and Stanton 2000). Measurements of acoustic backscatter using a scientific echosounder can be made from ships, buoys, or moorings and thus provide greater spatial coverage or longer time series than conventional sampling techniques such as net tows or diver observations. While video sampling methods (Davis et al. 1996; Benfield et al. 2001, 2003) provide some of the same advantages as acoustics, they are not used as extensively as acoustic surveys and typically have much smaller sampling volumes.

One of the difficulties in using acoustic backscatter to measure marine life in the ocean is that the data collected are indirect measures of biota. If aggregations of animals in a region are mono-specific and of similar size, theoretical backscatter models can be used to estimate their distribution and abundance (Hewitt and Demer 2000). If more than one frequency of sound is used, then more categories and size classes of animals may be distinguished and their abundance estimated (Martin et al. 1996; Brierley et al. 1998). However, these approaches require that the type of the scatterers present in the water column is known. Because of this, zooplankton samples are typically collected by net tows during an acoustic survey. These samples provide taxonomic and size information that can be used to predict the level of acoustic backscatter in the water column. 
This prediction is often referred to as the Forward Problem (FP). For a particular type of backscatterer (usually delineated by either size or taxonomy), the scattering contribution can be found by multiplying the numerical density of scatterers $\left(N_{i}\right.$, in units of $\left.\mathrm{m}^{-3}\right)$ present and the backscatter cross section for an individual scatterer of this type $\left(\sigma_{i}\right.$, in units of $\left.\mathrm{m}^{2}\right)$. The backscatter cross section is a function of several parameters including: the size, shape, composition, and orientation of the scatterer and acoustic frequency. The output of the FP is the volume backscatter coefficient $\left(s_{\mathrm{V}}\right.$, with units of $\mathrm{m}^{-1}$ ) which is found by summing the contributions from the different types of scatterers present

$s_{\mathrm{V}}=\sum_{i}\left(N_{i} \sigma_{i}\right)$

These calculated levels of backscatter are then compared with measured values from field surveys. Often echosounders record the volume backscatter strength $\left(S_{\mathrm{V}}\right.$, with units of $\left.\mathrm{dB}\right)$, which is related to $s_{\mathrm{V}}$ by

$S_{\mathrm{V}}=10 \log _{10}\left(s_{\mathrm{V}}\right)$

67 If the measured and predicted values agree, the Inverse Problem (IP) (using measured scattering values and theoretical scattering models to determine the number, size, or type of animals present) is more likely to be solved correctly. However, occasionally the predicted and measured volume backscatter strengths differ by an order of magnitude (or more), which can lead to large 
errors or uncertainty in solving the IP. For example, a $3 \mathrm{~dB}$ difference in $S_{\mathrm{V}}$ corresponds to a factor of two difference in the number of animals or their biomass. In practice, solutions to the $\mathrm{FP}$ are used in a diagnostic sense to determine how well the theoretical scattering models predict observed levels of backscatter in the ocean (Wiebe et al. 1996, 1997). These results often indicate that only a small subset of the animals present in the water column are acoustically important or, in some cases, that backscatter predictions based on the sampled zooplankton are unable to account for all of the observed backscatter and that another scattering source is unaccounted for in the FP analysis (Mair et al. 2005).

While nearly every acoustic survey relies on net tow data to groundtruth the acoustic data, many do not take complete advantage of all the available information provided by the net tow. Typically, FP calculations are performed to identify the acoustically dominant taxa in the water column, however the quantification of backscatter contributions from all of the taxa found in the water column is rarely done. While many taxa present in the water column will contribute negligibly to the overall level of backscatter (due to small size, low numerical density, or low scattering efficiency), there are often several scattering sources that contribute substantially to the overall level of measured acoustic backscatter. Furthermore, the vertical distribution of zooplankton in the water column varies, which may cause the taxa that is the largest acoustic scatterer to change as a function of depth. Many of the 
net tows used to ground-truth acoustic data can not provide this information, which may further complicate estimates of zooplankton abundance or distribution.

(1)

of backscattered acoustic energy. Suspended sediments, air bubbles, ocean mixing processes, and other biota have all been observed during acoustic surveys of zooplankton (Wiebe et al. 1997; Trevorrow 1998), however backscatter from non-biological processes is rarely quantified during field surveys.

Acoustic methods have been used to observe physical mixing processes in the ocean for many years (Thorpe and Brubaker 1983; Orr et al. 2000; Ross and Lueck 2005). It has only been in the last decade that theoretical scattering models for these processes have begun to be tested in the field. These models use the variations in temperature and salinity to calculate changes in the index of refraction and density in the water column that result from turbulence and other mixing processes. The acoustic scattering that occurs from these variations can then be predicted (Goodman 1990; Seim et al. 1995; Lavery et al. 2003).

Depending upon the mixing rates present (generally characterized by the dissipation rates of turbulent kinetic energy $(\epsilon)$ and temperature variance $(\chi))$, backscatter from turbulent microstructure can be equal to or greater 
than that from assemblages of zooplankton, particularly at the lower range of frequencies commonly used for acoustic surveys (i.e. $<100 \mathrm{kHz}$, see Fig. 1 in Warren et al. (2003)). Estimates of $S_{\mathrm{V}}$ from this mechanism range from -110 $\mathrm{dB}$ in calm waters with small temperature and salinity stratification to -60 $\mathrm{dB}$ or higher for regions of intense mixing such as the Bosporus Strait (Seim 1999).

This study examines the contributions of both biological and physical sources of backscatter to the water column in the Gulf of Maine. Contributions from each scattering source were quantified using theoretical scattering models and either net tow data or hydrographic profiles for multiple depth bins of the water column and multiple acoustic frequencies. The theoretical predictions of backscatter from the different scattering sources were used to correct the amount of measured backscatter in the water column to reflect scattering only from biological sources. The adjusted values of measured backscatter were then compared with measurements of zooplankton biomass.

\section{Materials and methods}

As part of a GLOBEC (GLOBal ocean ECosystem dynamics) process cruise studying the populations of Calanus in the basins of the Gulf of Maine, an acoustic survey was conducted in the eastern part of Wilkinson Basin (located between Georges Bank and Stellwagen Bank) in mid-October 1997 from the RV Endeavor (Table 1). To provide spectral information about 
the acoustic backscatter processes occurring in the water column, multiple frequency acoustic backscatter data were collected by BIOMAPER-II (BIoOptical Multi-frequency Acoustical and Physical Environmental Recorder) (Wiebe et al. 2002).

Multiple Opening and Closing Net and Environmental Sensing System (MOCNESS) tows (Wiebe et al. 1985) were conducted to collect zooplankton samples while BIOMAPER-II was concurrently recording acoustic backscatter data from the water column. Profiles of the temperature and salinity of the water column were made with CTD sensors onboard the MOCNESS and nearby higher-resolution CTD casts (Sea-Bird 9/11) from the vessel. Data from two sampling periods are presented herein, with samples from yearday 287 (CTD \#08, MOC \#07) and yearday 289 (CTD \#10, MOC \#09). The CTD and MOCNESS stations took place in the same general area (Table 1). These data sets (acoustic backscatter, zooplankton taxa and size, and temperature and salinity profiles) provided enough information to estimate the contributions from biological and physical sources of acoustic backscatter.

\section{Acoustic backscatter measurements}

BIOMAPER-II (Wiebe et al. 2002) is a towed body with numerous acoustic, environmental, video, and bio-optical sensors. The acoustic system consists of five pairs of transducers (operating at 43, 120, 200, 420, and 1000 $\mathrm{kHz}$ ), with one of each frequency looking upward and the other downward. 
The transducers have depth ranges of 200, 200, 150, 100, and 35 meters respectively with a vertical resolution of $1 \mathrm{~m}$ depth bins. Backscattered energy from each transducer and for each depth bin was recorded as echo-integrated volume backscattering strength every $12 \mathrm{~s}$. At typical survey speeds this ping rate corresponds to a horizontal range between pings of between 20 and $50 \mathrm{~m}$. The instrument was normally towed obliquely through the water column, however since additional equipment was in the water during these measurements, the tow-body was kept at a constant depth of approximately $5 \mathrm{~m}$ below the surface and slower tow-speeds resulted in a horizontal resolution between pings of approximately 10 to $15 \mathrm{~m}$. Because of this configuration and the limited depth range of the $1 \mathrm{MHz}$ transducer, only data from the downward-looking transducers at 43, 120, 200, and $420 \mathrm{kHz}$ were analyzed.

The acoustic data were processed and combined with data from the ESS (Environmental Sensing System) sensors that are also on board BIOMAPERII. The acoustic system was calibrated using standard target spheres before the cruise. The final data file provided echo integrated volume backscatter coefficients $\left(s_{\mathrm{V}}\right)$ for the water column along with date, time, position (latitude, longitude, instrument depth), temperature, salinity, fluorescence, turbidity, and other sensor data.

\section{Zooplankton net sampling}

Two $1-\mathrm{m}^{2}$ MOCNESS (Wiebe et al. 1985) tows were analyzed to 
identify, enumerate, and measure the zooplankton present in the waters of Wilkinson basin. A MOCNESS system consists of a series of nine nets, which enables specific depth strata to be sampled. Generally, net \#0 was open from the surface to the deepest point of the tow (ten to twenty meters above the bottom), the remaining nets (\#1-8) were opened and closed in succession every 25 to 50 meters during the return to the surface. The MOCNESS system also recorded the volume of water filtered by each net, the time that each net was opened and closed, depth, salinity, temperature, density, and fluorescence.

The nets were equipped with $333 \mu \mathrm{m}$ mesh and cod end buckets for collection of zooplankton and larval fish. Each cod end sample was split and stored in a buffered formalin solution. Post-processing of the samples consisted of silhouette photography of the animals (Davis and Wiebe 1985). These images were then examined under a microscope and the organisms were measured and identified by taxonomic group. Numerical density and biomass $\left(\mathrm{mg} \mathrm{m}^{-3}\right)$ were then calculated for each net for each taxonomic group (Davis and Wiebe 1985; Wiebe 1988).

\section{Scattering models}

try of the animal shape for several types of zooplankton were used to provide backscatter information for single animals for use in the FP analysis (Table 2).

These models have been developed previously and only slight modifications 
to some input parameters have been made in this work. These modifications were limited to body length-to-width relationships and the use of a simple fluid-like tissue model for certain gelatinous animals. The models represent the three main taxonomic types of zooplankton: fluid-like, elastic-shelled, and gas-bearing animals (Stanton et al. 1998).

\section{Biological scatterers}

Fluid-like models were used for copepods, euphausiids, amphipods, and other animals that have a thin shell (which does not support a shear wave) and a body composition that has similar density and sound speed to that of sea water. Fluid-like animals, which constituted the majority of zooplankton taxa that were encountered in the Gulf of Maine and Georges Bank region, were modeled as weakly-scattering, bent, fluid cylinders (Stanton et al. 1993b; Chu et al. 1993). The model has input parameters of: animal size (typically $a$, the radius), the acoustic frequency $(f)$ or wavenumber $\left(k=\frac{2 \pi f}{c}\right.$ where $c$ is the speed of sound in seawater), the ratio of sound speed and density between the scatterer and the surrounding fluid $(g$ and $h$ ), the length to width ratio of the animal $\left(\beta_{D}\right)$, and the orientation of the cylinder relative to the acoustic wave front. An assumed range of orientation angles based upon previous studies was used in modeling the euphausiids, as acoustic backscatter strength is a function of animal orientation (Sameoto 1980; McGehee et al. 1998; Warren et al. 2002). These animals often orient in a slight head-upward posture and were modeled with a $20^{\circ} \pm 20^{\circ}$ orientation distribution where $0^{\circ}$ is broadside 
orientation.

Modeling of other fluid-like animals was similar to that for the euphausiids. The value of $\beta_{D}$ was changed slightly to better reflect the body shapes of the other fluid-like animals (Table 2). Although Benfield et al. (2001) indicated that copepods may tend to orient themselves vertically in the water column, it was not known under what conditions this occurs, so an average over all orientations (uniform distribution) was used for all fluid-like animals except for euphausiids. Small changes in the values of $g$ and $h$ can cause large variations in the level of scattering from an animal (Chu et al. 2000; Chu and Wiebe 2005), so to minimize variability in this analysis, constant values of $g=1.0357$ and $h=1.0279$ (Foote 1990) were used for all fluid-like animals. It is not known whether the fluid-like animals found in this region have similar material properties as few data are available for animals other than copepods and euphausiids. If differences in the material properties exist for the fluid-like animals, that would cause larger variations in the predicted level of biologically-caused backscatter.

Elastic-shelled models were used for animals with a hard, elastic shell such as pteropods. Pelagic pteropods are typically very small $(<1 \mathrm{~mm}$ in diameter), but scatter a large amount of sound (per unit biomass) due to their dense shell. Other strong scatterers are gas-bearing animals such as siphonophores, where the scattering is caused by small gas bubbles used for buoyancy. Gelatinous animals (e.g. salps or medusae) or parts of animals (e.g. siphonophore 
nectophores) have not been modeled as thoroughly as the fluid-like or elasticshelled animals, however due to their body composition, it is believed that they scatter smaller amounts of sound by a mechanism similar to that of the fluid-like animals (Monger et al. 1998).

Several of these zooplankton models have been compared with measured scattering from individual animals (copepods, euphausiids, pteropods, and siphonophore nectophores and pneumatophores) (Stanton and Chu 2000; Stanton et al. 2000; Warren et al. 2001). The remaining zooplankton models have not specifically been tested against measurements from individual animals (amphipods, salps, polychaetes, chaetognaths, larval crustaceans, and cyphanautes), however these groups contain animals that are believed to be less important acoustically in this study due to either low numerical densities or very weak scattering characteristics.

The zooplankton backscatter models were combined with the abundance data from the MOCNESS tows to estimate the level of biologicallycaused scattering in the water column. For each animal type collected in a net tow, the backscatter contribution for an individual animal was determined using the appropriate scattering model. These contributions were summed over all animals collected and then divided by the volume of water sampled by the net to arrive at a volume backscatter coefficient for the depth stratum of the net. The contributions from all of the zooplankton were summed and the result was a predicted volume backscatter coefficient for biological sources. 


\section{Physical scattering processes}

Additional sources of backscatter that have been observed in the vicinity of Georges Bank include suspended sediments and bubbles. These scatterers are not believed to be important in this study due to the absence of sediment in net tows and the relatively calm sea state during the survey period. However, internal waves were seen in the acoustic record during the survey and thus the importance of backscatter from the resultant turbulent microstructure was examined.

Scattering from turbulent microstructure in the water column was analyzed in a parallel manner to that from zooplankton except that hydrographic data is used as the scattering model input instead of net tow data. Predictions from the theoretical backscatter model were made based on inputs of temperature, salinity, and the dissipation rates of turbulent kinetic energy and temperature variance (Seim 1999). The latter two values were estimated using temperature and salinity profiles from CTD casts taken either before or after the MOCNESS tow (Table 1) (Thorpe and Brubaker 1983; Warren et al. 2003). Although the ESS system on the MOCNESS provided temperature and salinity profiles, the sampling rate was limited to $0.25 \mathrm{~Hz}$, thus in order to resolve temperature and salinity variations at vertical scales less than a meter, the higher resolution CTD cast data (sampled at $24 \mathrm{~Hz}$ ) were used. 
net tow data so there are potential errors in using the CTD data to describe the structure of the water column when the net and acoustic data were recorded. However, hydrographic profiles for each CTD cast were consistent with the profile recorded by the corresponding MOCNESS tow. While this method is far from ideal for measuring values of turbulent kinetic energy and temperature variance, this method has been used previously to make realistic estimates that compare favorably to measurements of turbulent kinetic energy and temperature variance made in a similar region (Warren et al. 2003; Seim 1999). Sea state was relatively calm during these tows so we believe that errors due to vertical ship and CTD sensor movement are minimal. The estimated level of backscatter from microstructure was then averaged over the depth ranges sampled by each MOCNESS net so that it could be compared with the FP estimates from the zooplankton.

\section{Results}

Data are presented for two MOCNESS tows that occurred in nearby regions but differed in the types of zooplankton present, levels of acoustic backscatter, and water column structure. MOCNESS \#7 was lowered to 191 meters depth and was brought to the surface with a net closed and new net opened at 175, 150,125, 101, 74, 50, 26, and $0 \mathrm{~m}$. The lower nets contained large amounts of biomass $\left(150-200 \mathrm{mg} \cdot \mathrm{m}^{-3}\right)$ and were dominated by copepods and euphausiids (Figure 1a). The surface layer $(0-26 \mathrm{~m})$ had a higher level of biomass (over $100 \mathrm{mg} \cdot \mathrm{m}^{-3}$ ) than the other upper water column samples and 
was composed of copepods, polychaetes, chaetognaths, and amphipods.

[Figure 1 here]

Data from MOCNESS \# 9 show a different depth distribution of biomass, as well as a slightly more diverse taxonomic composition (Figure 1b). Nets were opened and closed at depths of 180, 153, 124, 99, 80, 60, 39, 20, and $0 \mathrm{~m}$. The zooplankton collected were dominated by an enormous number of salps $\left(2,500\right.$ animals $\mathrm{m}^{-3}$ ) near the surface (from 20 - $40 \mathrm{~m}$ depth) resulting in a large amount of biomass, nearly $1 \mathrm{~g} \cdot \mathrm{m}^{-3}$. There was also a substantial amount of biomass from 80 - 124 m that was composed of copepods and euphausiids, as well as a copepod-dominated bottom layer. The salp surface layer was an unusual occurrence on this cruise and no other net sample from the nine MOCNESS tows collected during the cruise had such a large amount of biomass. For both net tows, the dominant component of biomass at most depths were calanoid copepods.

As each MOCNESS tow was being conducted, BIOMAPER-II collected acoustic data while being towed at a depth of approximately 5 meters beside the ship. The acoustic data were offset horizontally from the MOCNESS samples by the amount of wire out on the net tow (at most a few hundred meters). In order to compare the acoustic regions with the MOCNESS information, the trajectory of the MOCNESS was overlaid on the acoustic plot to determine where each net sampled (Figure 2). 
[Figure 2 here]

The acoustic data for MOCNESS \#7 shows strong backscatter at the higher frequencies and weaker backscatter at $43 \mathrm{kHz}$ for much of the water column, although this pattern is reversed for the surface and deepest waters sampled (Figure 2a). Remnants of an internal wave were observed in the echogram and the upper layer of the wave, sampled by nets \# 7 and 8, had the strongest backscatter at the lowest acoustic frequency, while backscatter from the thick layer between 50 and $100 \mathrm{~m}$ was strongest at the highest frequencies. The echogram collected for MOCNESS \# 9 show a mid-water scattering layer that was sampled by nets \#4 - 6 with backscatter that had a similar relationship between scattering strength and acoustic frequency (Figure 2b). This frequency dependence is consistent with the backscatter model used for fluid-like scatterers (Warren et al. 2003). A near-surface scattering layer (sampled by net \# 7) shows the opposite effect (strongest backscatter at lower frequencies) that indicates the scattering was dominated by a different type of scatterer, possibly the large amount of salps or physical processes occurring at the thermocline.

The water column profile for MOCNESS \#7 showed a well-mixed region from 20 - $60 \mathrm{~m}$ with a steep temperature and salinity gradient above this layer and a shallower gradient below (Figure 3a). These mixing processes likely contributed to the backscatter observed between 15 and $100 \mathrm{~m}$ in the echogram (Figure 2a). The hydrographic data for MOCNESS \# 9 showed a 
well-mixed region in the upper $20 \mathrm{~m}$ of the water column with a large gradient in temperature, salinity, and density that occurred in the next $10 \mathrm{~m}$ (Figure 3b). There were several regions of potential or recent mixing (shown by unstable or nearly vertical sections of the density profile) occurring between 0 - $20 \mathrm{~m}, 60$ - $100 \mathrm{~m}$ and 140 - $180 \mathrm{~m}$, although there were smaller instabilities that occurred throughout the profile.

[Figure 3 here]

When FP predictions of backscatter were examined for the individual contributions for different animals or processes, the dominant scatterers for MOCNESS \# 7 were turbulent microstructure, euphausiids, and siphonophore pneumatophores, however the amphipod category (which included other larval crustaceans) and chaetognaths also caused appreciable amounts of backscatter (Figure 4). The other animals (particularly the abundant copepods) contributed little to the overall predicted scattering except at the highest frequencies. Copepods also contributed little to the predictions for MOCNESS \# 9. Turbulence, euphausiids, salps, and siphonophore pneumatophores were the largest contributors to the backscatter (Figure 5). It is striking that the copepods which were by far the largest contributors to biomass have such a small contribution to the predicted levels of backscatter. This is primarily a function of copepod size (a few mm in length) and acoustic frequency or wavelength. For the frequencies used in this survey, copepod backscatter is primarily a function of animal size and despite their numerical abundance in the net tow 
data, they are simply too small to contribute much to the predicted level of backscatter except at the higher frequencies.

\section{[Figures 4 and 5 here]}

The MOCNESS data provided information about the contributions that different zooplankton taxa make to the overall amount of biomass. Similarly, the relative contributions of different biological and physical sources to the total amount of predicted backscatter in the water column can be made by combining MOCNESS data, CTD data, and backscatter models. The relative contribution of each scattering source (each animal taxa and microstructure) was calculated for each MOCNESS net depth range and BIOMAPER-II frequency (Figures 6 and 7). The percentage contribution to the total predicted backscatter strength was found by dividing the predicted volume backscatter coefficient for each scatterer type by the overall calculated backscatter prediction. The percentage of total predicted scattering from physical (nonbiological) sources was calculated. The measured level of scattering (from the BIOMAPER-II data) was then reduced by this percentage to arrive at a corrected amount of measured backscatter that is believed to be from biological scatterers.

\section{[Figures 6 and 7 here]}

For example, the measured level of backscatter for MOCNESS \#9 from $0-20 \mathrm{~m}$ depth at $120 \mathrm{kHz}$ is $s_{\mathrm{V}}=1.58 \times 10^{-6} \mathrm{~m}^{-1}\left(S_{\mathrm{V}}=-58.0 \mathrm{~dB}\right)$. 
From Figure 7 , only $8 \%$ of the predicted backscatter for this sample is from biological sources. By multiplying the percentage of biologically-caused predicted backscatter and the measured level of backscatter, an estimate of the biologically-caused scatter in the water column was made, $s_{\mathrm{V}}=1.26 \times 10^{-7}$ $\mathrm{m}^{-1}\left(S_{\mathrm{V}}=-69.0 \mathrm{~dB}\right)$

Non-biological backscatter contributions were important for several regions sampled by MOCNESS \# 7 (Figure 6). The predicted contributions from microstructure were largest for the region between 20 and $100 \mathrm{~m}$ (which again corresponded to regions of mixing indicated in the hydrographic data) while euphausiids were the main scatterers for the deepest nets. Siphonophores contributed to the backscatter more for lower acoustic frequencies and were negligible at the highest frequency. The backscatter in the near surface was the most diverse with regard to scatterer type with nearly all taxonomic types contributing.

For MOCNESS \# 9, the deeper water column and surface layer were dominated by scattering from microstructure (Figure 7). These large backscatter contributions from turbulent microstructure occurred in the same regions that the hydrographic profile data indicated was well-mixed (0 - $20 \mathrm{~m}$ and 140 - $170 \mathrm{~m}$ ). Euphausiids were the dominant scatterers in the mid-water depths, with siphonophore pneumatophores and nectophores also contributing. Salps were extremely weak scatterers and while outnumbering the other animals and dominating the biomass in the near-surface, they contributed only $30 \%-60 \%$ 
to the total backscatter in that region.

If the FP is well-posed and one taxa dominates the measured scattering, then there should be a relationship between biomass and measurements of backscatter strength. Both biomass and volume backscatter cross-section $\left(s_{v}\right)$ are linear functions (for a particular taxa) of the number of animals. Therefore it is likely that a relationship between biomass and volume scattering strength should exist. The relationship between biomass and measured backscatter may not be linear however if more than one scattering process (or taxonomic type or size class) is substantially contributing to the measured backscatter.

The biomass and acoustic backscatter data sets from both MOCNESS tows were combined and the regression between the logarithm of biomass and measured acoustic backscatter strength $\left(S_{v}\right.$, a logarithmic measure of acoustic backscatter) was found for each acoustic frequency. The log of both biomass and backscatter was used as some of the acoustic data (specifically predicted backscatter for some scatterer types) ranged over nearly five orders of magnitude. The backscatter model used for salps has not been as well tested, by comparing theoretical backscatter predictions with measured backscatter from individual animals, as the backscatter models used for other animals. Because of this fact and the extremely high biomass of salps caught in net \#7 of MOCNESS \#9, the data from this net were not included in this analysis.

There was not a strong relationship (all $\mathrm{r}^{2}$ values $<0.4$ ) between log- 
transformed biomass and measured backscatter levels for any of the four frequencies used (Figure 8). A poor relationship between zooplankton biomass and acoustic backscatter is likely to occur when non-zooplankton scatterers are contributing to the measured amount of acoustic backscatter. This result was not surprising since turbulent microstructure was predicted to contribute greatly to the measured backscatter for some portions of the water column.

[Figures 8 and 9 here]

A similar analysis was performed for biomass and biologically-caused backscatter (Figure 9). When backscatter attributed to physical processes was removed, the relationship between log measures of biomass and acoustic backscatter was more linear. Regression coefficients improved for all frequencies indicating a better correlation between biomass and backscatter. It must be noted that the regression coefficients for each frequency are still fairly small $\left(\mathrm{r}^{2}\right.$ ranged from 0.38 to 0.52$)$, however these values are a factor of two or three larger than if the source of the backscatter is not identified. By accounting for the source of acoustic backscatter using hydrographic and net tow information, this method can be used to improve the use of acoustic backscatter data as a measure of zooplankton biomass.

\section{Discussion}

One of the goals of acoustic surveys is to estimate zooplankton biomass and this requires that the relationship between biomass and acoustic backscat- 
ter is well understood. The data presented here indicate that improvements can be made in the interpretation of field collected survey data if the contributions of all scattering sources are quantified. The relative importance of physical and biological sources of acoustic backscatter will vary with location in the ocean and certainly some regions will not have substantial backscatter from physical processes in the water column while other areas (such as the sites in this study which have internal waves present) will have significant contributions to the backscatter from non-biological sources. The modeling efforts outlined in this work provide one way of determining if physical sources of backscatter will need to be accounted for when interpreting acoustic backscatter survey data. However, these improvements are just one step of many that need to be taken in order that acoustic surveys may provide estimates of zooplankton abundance that are accurate and ecologically useful. Given that biomass and predictions of biologically-caused backscatter are not perfectly correlated, sources of error in the analysis, such as inaccuracies in the backscatter models used, must be examined.

The zooplankton backscatter models for fluid-like, elastic-shelled, and gas-bearing zooplankton have been used previously in the analysis of fieldcollected data (Wiebe et al. 1996, 1997; Greene et al. 1998), however there are many variables used in these models that are inadequately understood such as animal behavior and orientation or the material properties ( $g$ and $h$ ) of the zooplankton. A better understanding of the scattering model inputs 
would reduce errors associated with these types of animals. Furthermore, there are numerous types of animals (salps, polychaetes, chaetognaths, gelatinous zooplankton) whose backscatter characteristics have neither been modeled or measured in a laboratory environment.

Uncertainty about the inputs to the backscatter models is a concern for the microstructure model as well. Proper instrumentation was not present to measure the dissipation rates of turbulent kinetic energy and temperature variance, which are vital inputs into the theoretical microstructure backscatter models, so the method used to estimate these inputs was not ideal. While this method provided reasonable estimates of $\epsilon$ and $\chi$, it likely overestimated the scattering contributions from microstructure. For example, some regions of MOCNESS \# 9 have microstructure-caused $s_{\mathrm{V}}$ values that were larger than the backscatter measured by BIOMAPER-II (Figure 5). Further complicating this issue is the possibility that the vertical migration of animals may be creating significant amounts of turbulence and mixing (Huntley and Zhou 2004; Kunze et al. 2006).

Other possible sources of error in the FP analysis include erroneous zooplankton abundance and composition data and inaccurate measurements of the acoustic backscatter. Net tow information from MOCNESS systems has been used for several decades and sampling errors from it are likely limited to net avoidance by large zooplankton (Wiebe et al. 2004) and gelatinous animals being destroyed by the net mesh. Finally, the under-sampling of animals either 
by nets (e.g. large euphausiids or small fish) or lower acoustic frequencies (e.g. copepods) will cause errors in the FP analysis. One approach that has been used in the analysis of acoustic scattering data (Warren et al. 2003) is to use the net tow estimates of numerical density as a lower bound on the true value (since you can not have more animals in a net than are present in the water column) and use the acoustically-inferred estimates of biomass as an upper bound (since these rely on measures of backscatter strength that likely contain contributions from other scattering sources). In this manner, combining acoustic and net tow data can provide an upper and lower estimate of the abundance of zooplankton in the water column.

This study also demonstrates the importance of resolving the changes in biological and physical backscatter sources within the water column. A multiple net system, or other method such as video or optical ground-truthing, may be a necessary piece of equipment to accurately assess acoustic surveys of zooplankton biomass, particularly where the taxonomic components of the zooplankton community are diverse. Providing this vertical resolution and ground-truthing of the acoustic data also allows us to observe partitioning of the water column into different habitats that would not be apparent from either the acoustic data alone or a vertically integrating net tow. While some regions of the ocean do have patches with a single dominant taxa (e.g. Antarctic krill), the variation in abundance and distribution of zooplankton taxa observed over a $200 \mathrm{~m}$ vertical span in this study demonstrates the importance 
of measuring and quantifying these changes.

The difference between predictions of $S_{\mathrm{V}}$ and those values that would perfectly correlate with the biomass data are on the order of 5 - $10 \mathrm{~dB}$ (assuming that the biomass data are accurate) (Figure 9). These differences become very large when backscatter strengths are converted to estimates of biomass, therefore these predictions result in estimates of zooplankton biomass that are correct to roughly an order of magnitude. In certain cases this level of error may be acceptable, but further work is needed to reduce this uncertainty. Without accounting for the source of acoustic scattering in the water column, estimates of biomass from acoustics are likely to have even larger errors.

\section{Acknowledgements}

The Captain, crew, and scientists of cruise EN307 of the Endeavor were invaluable during the maiden voyage of BIOMAPER-II. Nancy Copley and Mari Butler provided assistance and instruction in the silhouette photograph analysis of the MOCNESS samples. Harvey Seim graciously provided his scattering model code. This work was supported by the Office of Naval Research (Grants \#N00014-00-1-0052 and N00014-01-1-0166). This is contribution \#XXX of the Marine Sciences Research Center at Stony Brook University, \#XXX of the Woods Hole Oceanographic Institution and \#XXX of the Georges Bank GLOBEC program. 


\section{References}

Anderson, V.C. 1950. Sound scattering from a fluid sphere. J. Acoust. Soc. Am. 22: 426-431.

Benfield, M.C., Davis, C.S., and Gallager, S.M. 2001. Estimating the insitu orientation of Calanus finmarchicus on Georges Bank using the Video Plankton Recorder. Plankton Biol. Ecol. 47: 69-72.

Benfield, M.C., Lavery, A.C., Wiebe, P.H., Greene, C.H., Stanton, T.K., and Copley, N.J. 2003. Distributions of physonect siphonulae in the Gulf of Maine and their potential as important sources of acoustic scattering. Can.

J. Fish. Aquat. Sci. 60: 759-772.

Brierley, A.S., Ward, P., Watkins, J.L., and Goss, C. 1998. Acoustic discrimination of Southern Ocean zooplankton. Deep-Sea Res. II. 45: 1155-1173.

Chu, D. and Wiebe, P.H. 2005. Measurements of sound speed and density contrasts of zooplankton in Antarctic waters. ICES J. Mar. Sci. 62: 818831.

Chu, D., Foote, K.G., and Stanton, T.K. 1993. Further analysis of target strength measurements of Antarctic krill at 38 and $120 \mathrm{kHz}$ : Comparison with deformed cylinder model and inference of orientation distribution. J. Acoust. Soc. Am. 93: 2985-2988.

Chu, D., Wiebe, P.H., and Copley, N. 2000. Inference of material properties of zooplankton from acoustic and resistivity measurements. ICES J. Mar. Sci. 57: 1128-1142. 
Davis, C.S., and Wiebe, P.H. 1985. Macrozooplankton biomass in a warmcore Gulf Stream ring: Time series changes in size, structure, and taxonomic composition and vertical distribution. J. Geophys. Res. 90: 8871-8884.

Davis, C.S., Gallager, S.M., Marra, M., and Stewart, W.K. 1996. Rapid visualization of plankton abundance and taxonomic composition using the Video Plankton Recorder. Deep-Sea Res. 43: 1947-1970.

Foote, K.G. 1990. Speed of sound in Euphausia superba. J. Acoust. Soc. Am. 87: 1405-1408.

Foote, K.G., and Stanton, T.K. 2000. Acoustical Methods. In ICES Zooplankton Methodology Manual. Edited by R. Harris, P.H. Wiebe, J. Lenz, H.R. Skjoldal, and M. Huntley. Academic Press, London. pp. 223-258.

Goodman, L. 1990. Acoustic scattering from ocean microstructure. J. Geophys. Res. 95: 11557-11573.

Greene, C.H., Wiebe, P.H., Pershing, A.J., Gal, G., Popp, J.M., Copley, N.J., Austin, T.C., Bradley, A.M., Goldsborough, R.G., Dawson, J., Hendershott, R., and Kaartvedt S. 1998. Assessing the distribution and abundance of zooplankton: a comparison of acoustic and net-sampling methods with DBAD MOCNESS. Deep-Sea Res. II. 45: 1219-1237.

Hewitt, R.P., and Demer, D.A. 2000. The use of acoustic sampling to estimate the dispersion and abundance of euphausiids, with an emphasis on Antarctic krill, Euphausia superba. Fish. Res. 47: 215-229.

Holliday, D.V., and Pieper, R.E. 1995. Bioacoustical oceanography at high 
frequencies. ICES J. Mar. Sci. 52: 279-296.

Huntley, M.E., and Zhou, M. 2004. Influence of animals on turbulence in the sea. Mar. Ecol. Prog. Ser. 273: 65-79.

Kunze, E., Dower, J.F., Beveridge, I., Dewey, R., and Bartlett, K.P. 2006. Observations of biologically generated turbulence in a coastal inlet. Science (Washington, D.C.), 313: 1768-1770.

Lavery, A.C., Schmitt, R.W., and Stanton, T.K. 2003. High-frequency acoustic scattering from turbulent oceanic microstructure: The importance of density fluctuations. J. Acoust. Soc. Am. 114: 2685-2697.

Mair, A.M., Fernandes, P.G., Lebourges-Dhaussy, A., and Brierley, A.S. 2005. An investigation into the zooplankton composition of a prominent $38-\mathrm{kHz}$ scattering layer in the North Sea. J. Plankt. Res. 27: 623-633.

Martin, L.V., Stanton, T.K., Wiebe, P.H., and Lynch, J.F. 1996. Acoustic classification of zooplankton. ICES J. Mar. Sci. 53: 217-224.

McGehee, D.E., O’Driscoll, R.L., and Martin-Traykovski, L.V. 1998. Effects of orientation on acoustic scattering from Antarctic krill at $120 \mathrm{kHz}$. Deep-Sea Res. II. 45: 1273-1294.

Monger, B.C., Chinniah-Chandy, S., Meir, E., Billings, S., Greene, C.H., and Wiebe, P.H. 1998. Sound scattering by the gelatinous zooplankters Aequorea victoria and Pleurobrachia bachei. Deep-Sea Res. II. 45: 1255-1271.

Orr, M.H., Haury, L.R., Wiebe, P.H., and Briscoe, M.G. 2000. Backscatter of high-frequency $(200 \mathrm{kHz})$ acoustic wavefields from ocean turbulence. J. Acoust. Soc. Am. 108: 1595-1601. 
Ross, T., and Lueck, R. 2005. Estimating turbulent dissipation rates from acoustic backscatter. Deep-Sea Res. 52: 2353-2365.

Sameoto D.D. 1980. Quantitative measurements of Euphausiids using a 120$\mathrm{kHz}$ sounder and their in situ orientation. Can. J. Fish. Aquat. Sci. 37: 693-702.

Seim H.E. 1999. Acoustic backscatter from salinity microstructure. J. Atmos. Ocean. Tech. 16: 1491-1498.

Seim, H.E., Gregg, M.C., and Miyamoto, R.T. 1995. Acoustic backscatter from turbulent microstructure. J. Atmos. Ocean. Tech. 12: 367-380.

Stanton, T.K., and Chu, D. 2000. Review and recommendations for modeling of acoustic scattering by fluid-like elongated zooplankton: Euphausiids and copepods. ICES J. Mar. Sci. 57: 793-807.

Stanton, T.K., Chu, D., Wiebe, P.H., and Clay, C.S. 1993a. Average echoes from randomly oriented random-length finite cylinders: Zooplankton models. J. Acoust. Soc. Am. 94: 3463-3472.

Stanton, T.K., Clay, C.S., and Chu, D. 1993b. Ray representation of sound scattering by weakly scattering deformed fluid cylinders: Simple physics and application to zooplankton. J. Acoust. Soc. Am. 94: 3454-3462.

Stanton, T.K., Wiebe, P.H., Chu, D., Benfield, M.C., Scanlon, L., Martin, L., and Eastwood, R.L. 1994. On acoustic estimates of zooplankton biomass. ICES J. Mar. Sci. 51: 505-512.

Stanton, T.K., Chu, D., and Wiebe, P.H. 1998. Sound Scattering by several zooplankton groups. II. Scattering Models. J. Acoust. Soc. Am. 103: 236- 
Stanton, T.K. Chu, D., Wiebe, P.H., Eastwood, R.L., and Warren J.D. 2000. Acoustic scattering by benthic and pelagic shelled animals. J. Acoust. Soc. Am. 108: 535-550.

Thorpe, S.A., and Brubaker, J.M. 1983. Observations of sound reflection by temperature microstructure. Limnol. Oceanogr. 28: 601-613.

Trevorrow M.V. 1998. Observations of internal solitary waves near the Oregon coast with an inverted echo sounder. J. Geophys. Res. 103: 7671-7680.

Warren, J.D., Stanton, T.K., Benfield, M.C., Wiebe, P.H., Chu, D., and Sutor, M. 2001. In situ measurements of acoustic target strengths of gas-bearing siphonophores. ICES J. Mar. Sci. 58: 740-749.

Warren, J.D., Stanton, T.K., McGehee, D.E., and Chu, D. 2002. Effect of animal orientation on acoustic estimates of zooplankton properties. IEEE J. Oceanic Eng. 27: 130-138.

Warren, J.D., Stanton, T.K., Wiebe, P.H., and Seim, H.E. 2003. Inference of biological and physical parameters in an internal wave using multiple frequency acoustic scattering data. ICES J. Mar. Sci. 60: 1033-1046.

Wiebe P.H. 1988. Functional regression equations for zooplankton displacement volume, wet weight, dry weight, and carbon: A correction. Fish. Bull. 86: 833-835.

Wiebe, P.H., Morton, A.W., Bradley, A.M., Backus, R.H., Craddock, J.E., Barber, V., Cowles, T.J., and Flierl, G.R. 1985. New developments in the MOCNESS, an apparatus for sampling zooplankton and micronekton. Mar. 
Biol. 87: 313-323.

Wiebe, P.H., Mountain, D.G., Stanton, T.K., Greene, C.H., Lough, G., Kaartvedt, S., Dawson, J., and Copley, N. 1996. Acoustical study of the spatial distribution of plankton on Georges Bank and the relationship between volume backscattering strength and the taxonomic composition of the plankton. Deep-Sea Res. II. 43: 1971-2001.

Wiebe, P.H., Stanton, T.K., Benfield, M.C., Mountain, D.G., and Greene, C.H. 1997. High-frequency acoustic volume backscattering in the Georges Bank coastal region and its interpretation using scattering models. IEEE J. Oceanic Eng. 22: 445-464.

Wiebe, P.H., Stanton, T.K., Greene, C.H., Benfield, M.C., Sosik, H.M., Austin, T., Warren, J.D., and Hammer, T. 2002. BIOMAPER II: an integrated instrument platform for coupled biological and physical measurements in coastal and oceanic regimes. IEEE J. Oceanic Eng. 27: 700-716.

Wiebe, P.H., Ashjian, C., Gallager, S., Davis, C., Lawson, G., and Copley, N. 2004. Using a high powered strobe light to increase the catch of Antarctic krill. Mar. Biol. 144: 493-502. 
Table 1

Location and time of the CTD vertical profiles and MOCNESS tows used in this study collected in October 1997 from the RV Endeavor.

\begin{tabular}{lllll}
\hline Event & Julian Yearday & Latitude $(\mathrm{N})$ & Longitude $(\mathrm{W})$ & Begin/End \\
\hline CTD 08 & 287.451 & $42^{\circ} 14.97^{\prime}$ & $68^{\circ} 44.77^{\prime}$ & Begin \\
& 287.467 & $42^{\circ} 14.97^{\prime}$ & $68^{\circ} 44.77^{\prime}$ & End \\
MOC 07 & 287.620 & $42^{\circ} 24.04^{\prime}$ & $68^{\circ} 49.03^{\prime}$ & Begin \\
& 287.686 & $42^{\circ} 24.93^{\prime}$ & $68^{\circ} 44.22^{\prime}$ & End \\
CTD 10 & 289.535 & $42^{\circ} 25.08^{\prime}$ & $68^{\circ} 44.49^{\prime}$ & Begin \\
& 289.562 & $42^{\circ} 25.08^{\prime}$ & $68^{\circ} 44.49^{\prime}$ & End \\
MOC 09 & 289.896 & $42^{\circ} 28.70^{\prime}$ & $68^{\circ} 45.00^{\prime}$ & Begin \\
& 289.949 & $42^{\circ} 30.97^{\prime}$ & $68^{\circ} 46.69^{\prime}$ & End \\
\hline
\end{tabular}


Table 2

Citations and parameters for the acoustic backscattering models used in the Forward Problem calculations. $\beta_{D}$ is the length to width ratio $\left(\frac{L}{D}\right)$ of the animal, $\mathrm{R}$ is the reflection coefficient.

\begin{tabular}{|c|c|}
\hline Scatterer & Scattering Model Citation, Parameters \\
\hline Euphausiids & $\begin{array}{l}\text { Stanton et al. (1993a); Stanton and Chu (2000), } \\
\beta_{D}=5.3576, \mathrm{R}=0.058, \\
\text { "head-up" orientation distribution }\left(20^{\circ} \pm 20^{\circ}\right)\end{array}$ \\
\hline $\begin{array}{l}\text { Copepods and Larval } \\
\text { Crustaceans }\end{array}$ & $\begin{array}{l}\text { Stanton et al. (1993a); Stanton and Chu (2000), } \\
\beta_{D}=2.5497, \mathrm{R}=0.058, \\
\text { uniform orientation distribution }\left(0-360^{\circ}\right)\end{array}$ \\
\hline Amphipods & $\begin{array}{l}\text { Stanton et al. (1993a); Stanton and Chu (2000), } \\
\beta_{D}=3.0021, \mathrm{R}=0.058, \\
\text { uniform orientation distribution }\left(0-360^{\circ}\right)\end{array}$ \\
\hline Polychaetes and & Stanton et al. (1993a); Stanton and Chu (2000), \\
\hline Chaetognaths & $\begin{array}{l}\beta_{D}=17.151, \mathrm{R}=0.058 \\
\text { uniform orientation distribution }\left(0-360^{\circ}\right)\end{array}$ \\
\hline Limacina Pteropods & Stanton et al. (1994), $\mathrm{R}=0.5$ \\
\hline Siphonophore Nectophores & Monger et al. (1998), $\mathrm{R}=0.028$ \\
\hline Siphonophore Pneumatophores & Anderson (1950) \\
\hline Salps & Monger et al. (1998), $\mathrm{R}=0.028$ \\
\hline Microstructure & Seim (1999) \\
\hline
\end{tabular}


674

\section{Figure Captions}

Fig. 1. Total biomass estimated from MOCNESS \# 7 (a) and 9 (b) data with the relative contributions of the different taxonomic groups. Several taxa are grouped together in the plot including: amphipods and other crustaceans including larvae ("Crustaceans"); polychaetes, chaetognaths ("Worms"), pteropods and gelatinous zooplankton ("Others"). The vertical thickness of the bar corresponds to the depth range sampled. For MOCNESS \#7 the lower depths were composed primarily of copepods and euphausiids with some gelatinous animals, while the surface layers also contained small amounts of polychaetes, chaetognaths, and siphonophore fragments. MOCNESS \#9 sampled a large sub-surface layer of salps (over 2500 animals $\mathrm{m}^{-3}$ ) which dominated the biomass sample. The remaining nets were composed of primarily copepods and euphausiids.

Fig. 2. BIOMAPER-II echograms for 43, 120, 200, and $420 \mathrm{kHz}$ for MOCNESS \# 7 (a) and 9 (b). The white line indicates the path of the net system, black circles indicate where nets were opened and closed. Different regions of the water column have different measured backscattering strengths for the various frequencies. Remnants of an internal wave (undulating backscattering layers) were observed during MOCNESS \# 7, while MOCNESS \# 9 measured a the strong near-surface layer at $20 \mathrm{~m}$ depth which is seen most strongly in the 43 kHz echogram. 
Fig. 3. Temperature, salinity and density profiles collected by the ESS system onboard MOCNESS \# 7 (a) and 9 (b). Regions of potential mixing and turbulent microstructure are indicated by nearly-vertical or unstable sections of the density profile such as 30 - 80 m for MOCNESS \#7 and 0 - 20 m, 60 - 100 $\mathrm{m}$, and 140 - $180 \mathrm{~m}$ for MOCNESS \#9.

Fig. 4. Forward problem calculations for each class of scatterer for MOCNESS \#7. The different acoustic frequencies (43, 120, 200 and $420 \mathrm{kHz}$ ) are represented by squares, stars, circles, and diamonds respectively. Small copepods had body lengths less than $2.5 \mathrm{~mm}$. Data points that lie above the diagonal line indicate that the FP underestimates the scattering, while points below the line are overestimates. Microstructure, siphonophore pneumatophores, chaetognaths, and euphausiids are the strongest contributors to the predicted levels of backscattering.

Fig. 5. Forward problem calculations for each class of scatterer for MOCNESS \#9. The different acoustic frequencies (43, 120, 200 and $420 \mathrm{kHz}$ ) are represented by squares, stars, circles, and diamonds respectively. Small copepods had body lengths less than $2.5 \mathrm{~mm}$. Data points that lie above the diagonal line indicate that the FP underestimates the scattering, while points below the line are overestimates. Microstructure, salps, siphonophore pneumatophores and euphausiids are the strongest contributors to the predicted levels of backscattering. 
Fig. 6. Percentage breakdown of Forward Problem calculations for each net and acoustic frequency of MOCNESS \#7. Turbulent microstructure contributes large amounts to the total backscattering in the mid-water regions, while euphausiids backscattered a majority of the sound in the deeper water. Siphonophores contribute greatly at the lower frequencies, but not at the higher ones. The surface region $(0-20 \mathrm{~m})$ had a very diverse group of scatterers.

Fig. 7. Percentage breakdown of Forward Problem calculations for each net and acoustic frequency of MOCNESS \#9. Euphausiids dominate the backscattering in the mid-water depths, while turbulence contributes strongly both near the bottom and near the surface. The salps which dominated the biomass in the near-surface net, contribute only $30 \%$ to $60 \%$ to the total backscattering for that region.

Fig. 8. The relationship between the logarithm of biomass and measurements of acoustic backscatter strength for MOCNESS \#7 (squares) and 9 (circles), excluding net \#7 from MOCNESS \#9. Most frequencies show little correlation between these two variables except for the highest frequency $(420 \mathrm{kHz})$.

Fig. 9. The relationship between the logarithm of biomass and predictions of biologically-caused acoustic backscatter for MOCNESS \#7 (squares) and 9 (circles), excluding net \#7 from MOCNESS \#9. All the acoustic frequencies show improved regressions and fairly linear relationships for the data. 


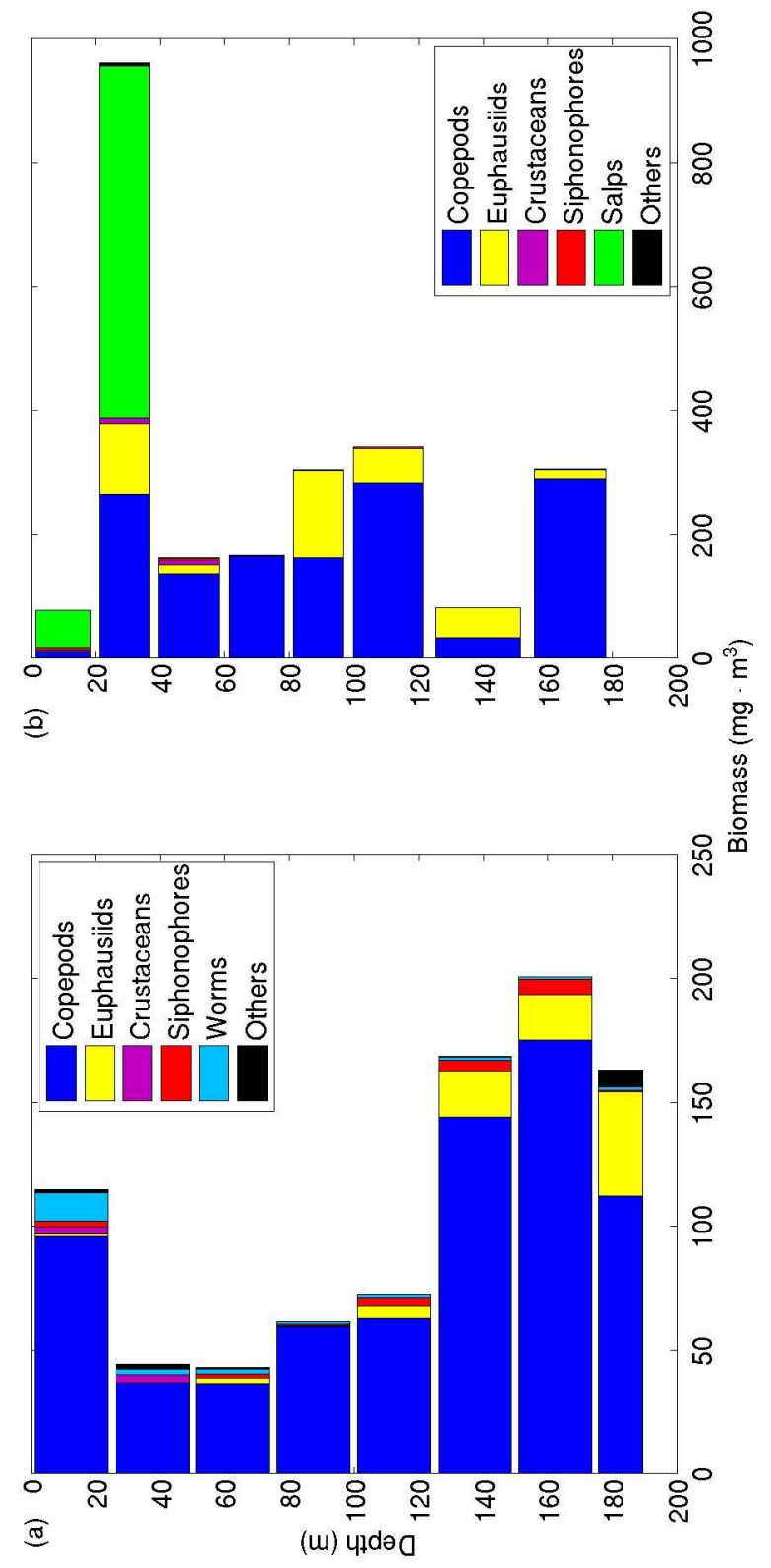

Fig. 1. 


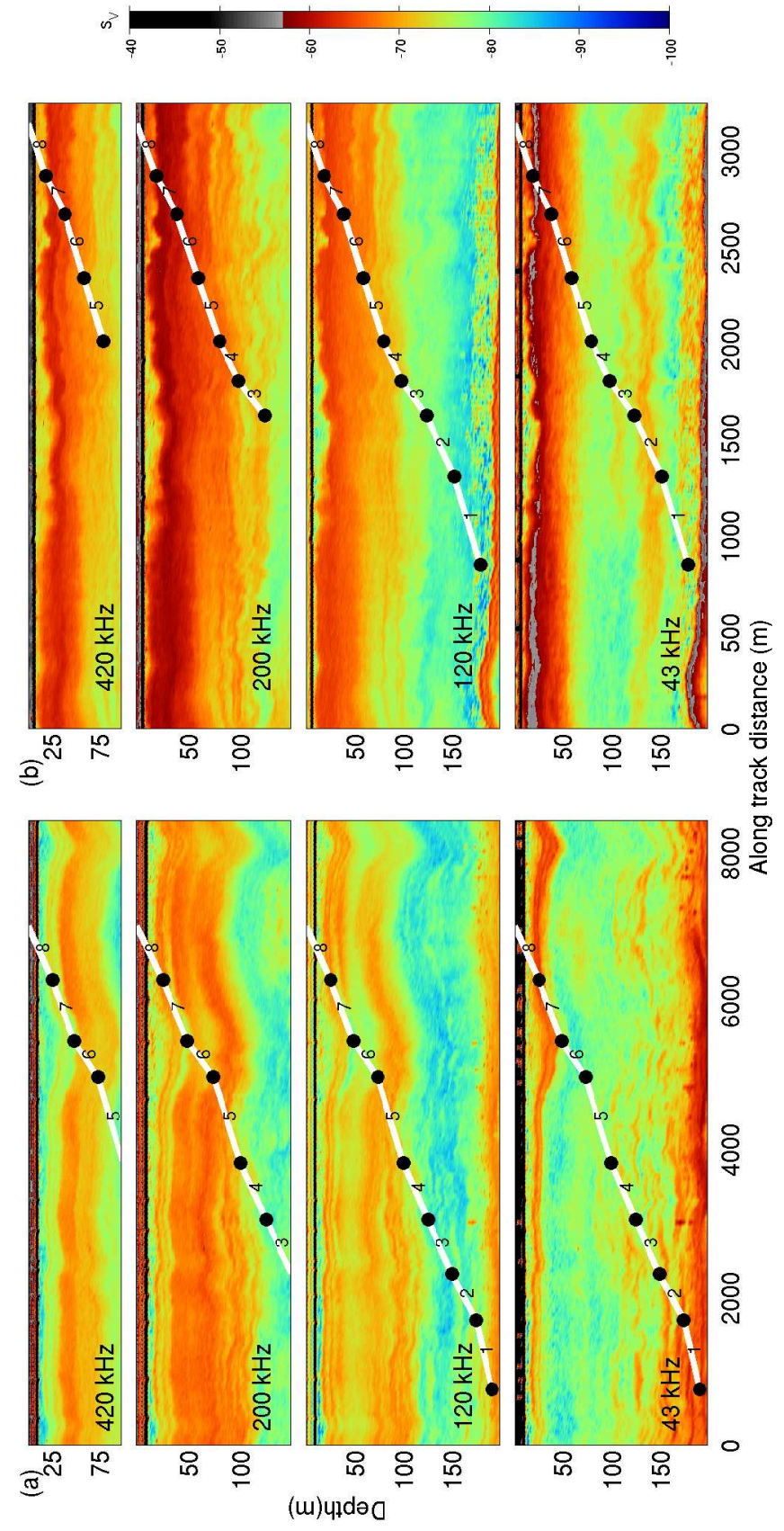

Fig. 2. 

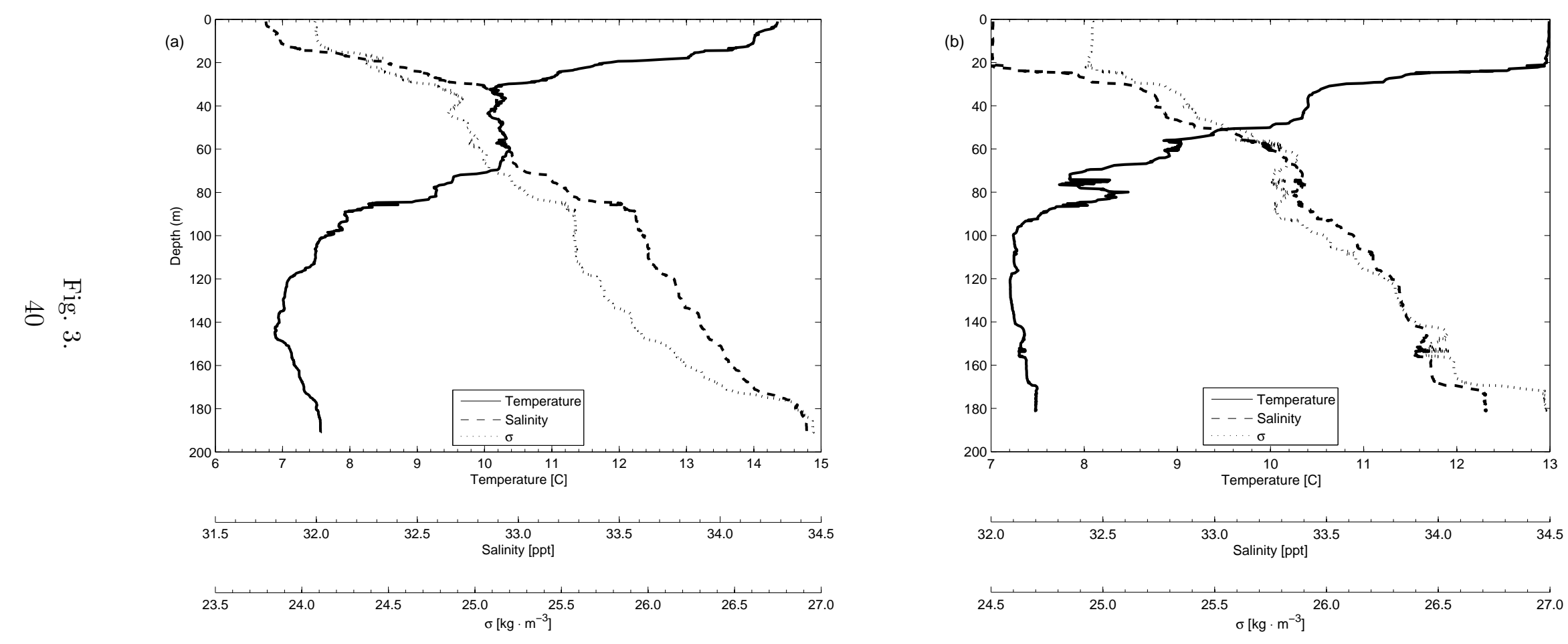

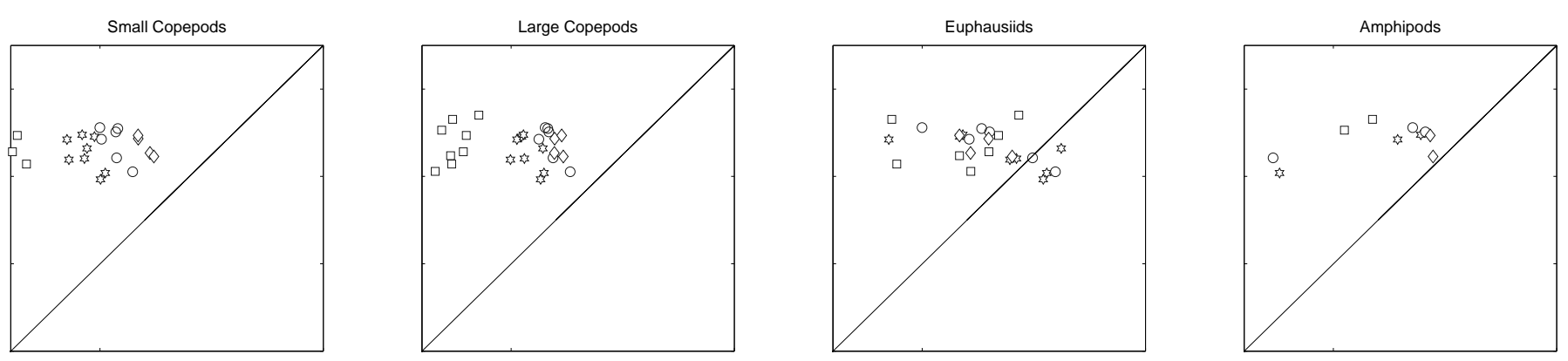

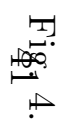
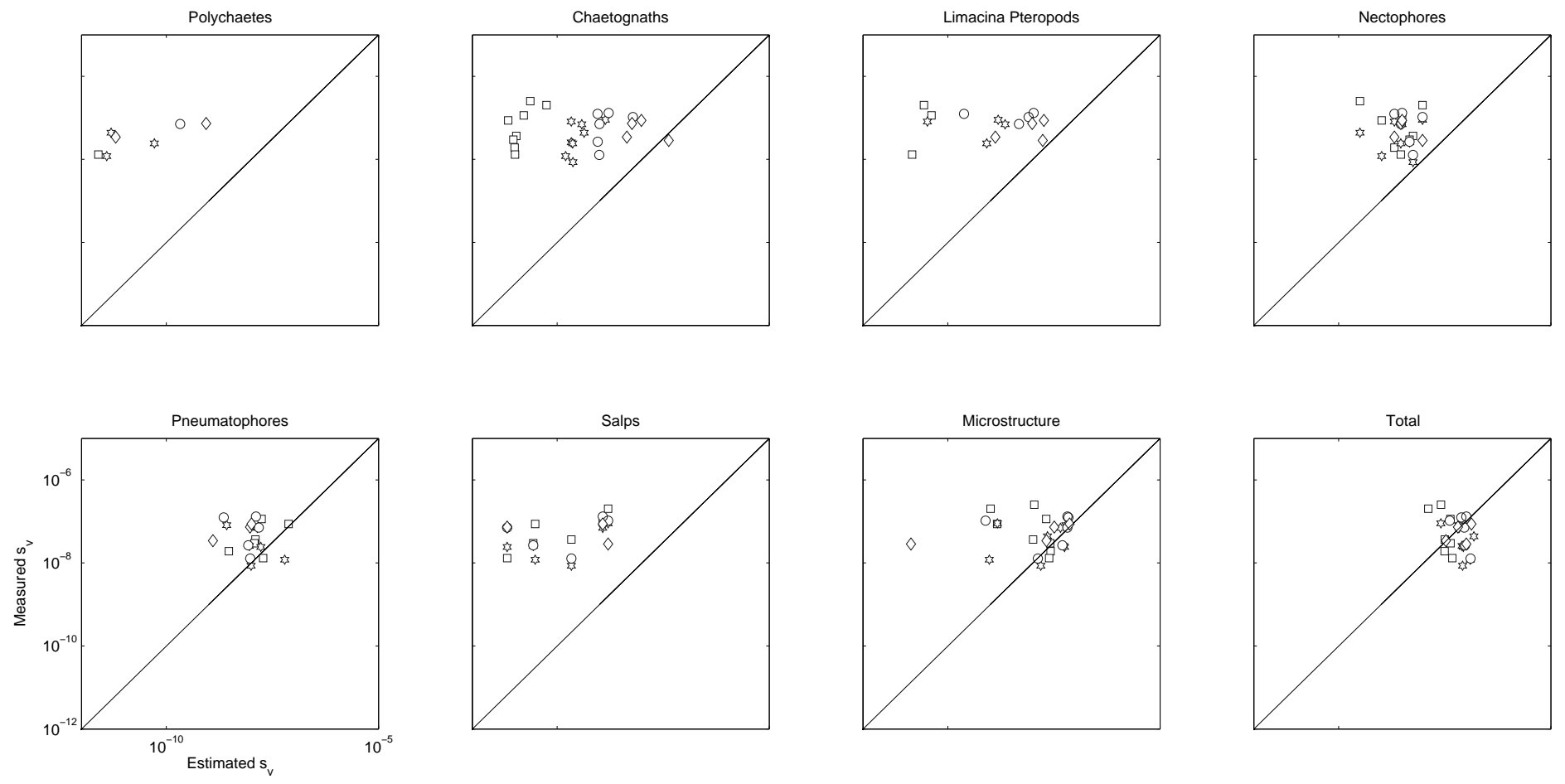

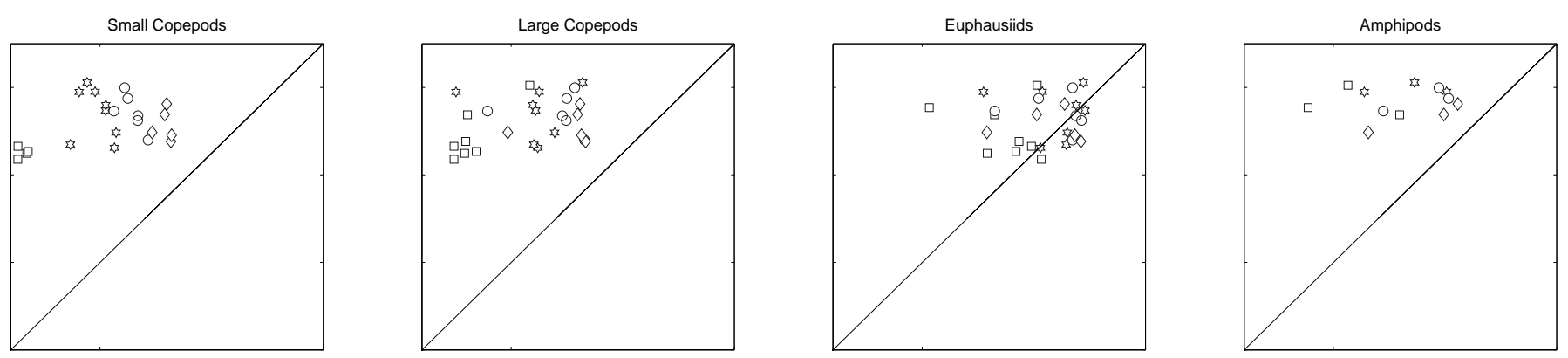

תִ
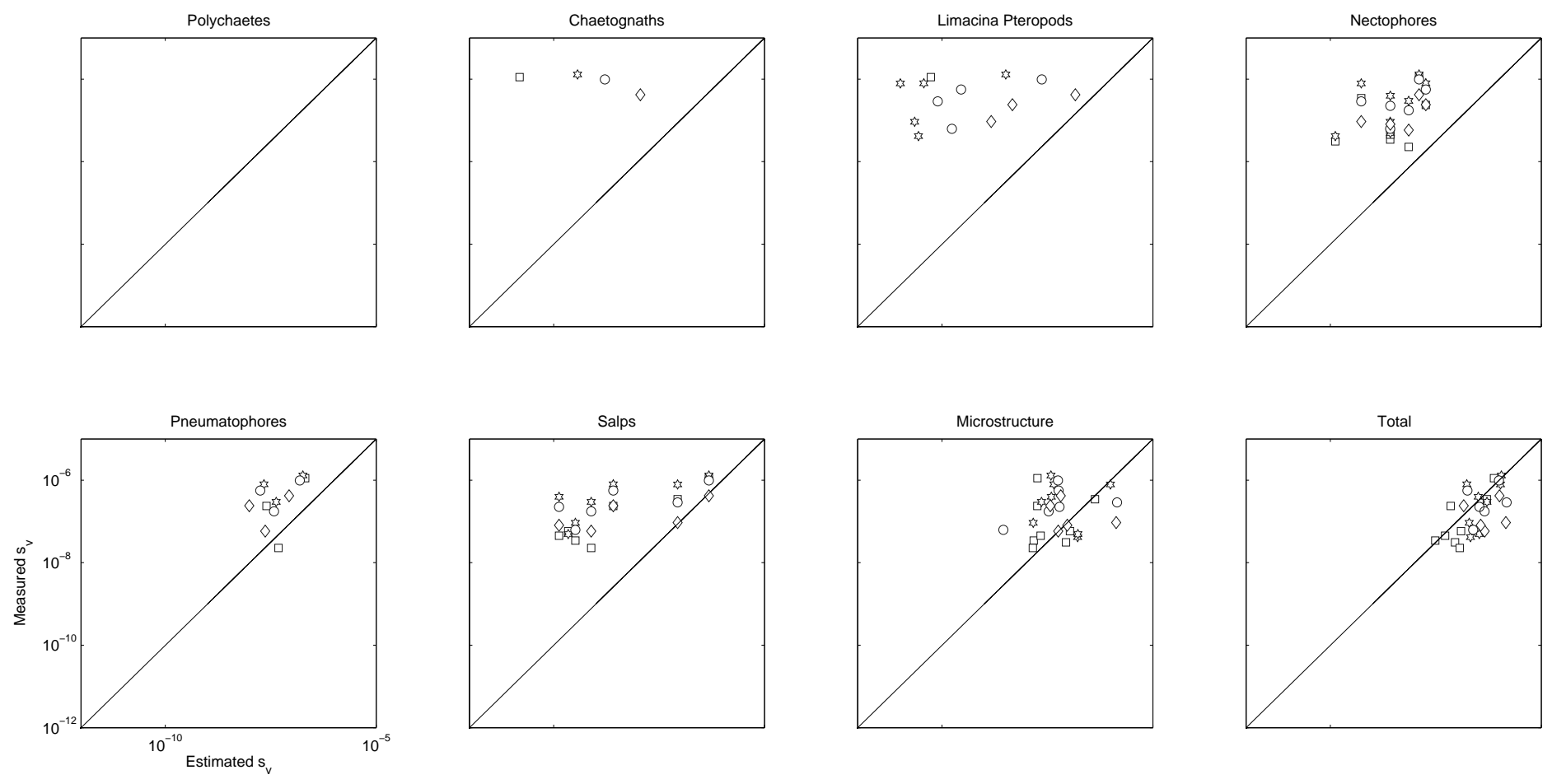


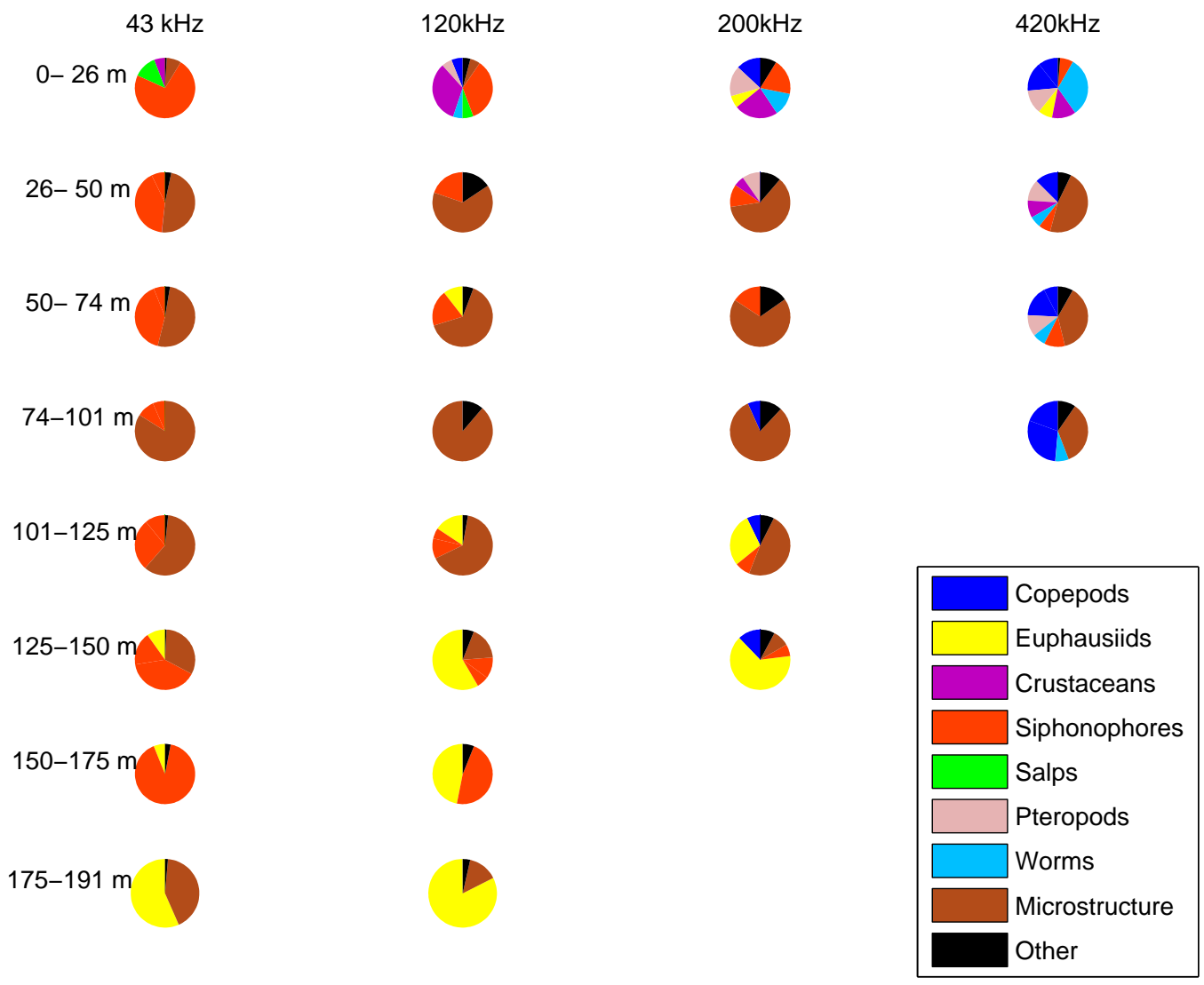

Fig. 6 . 


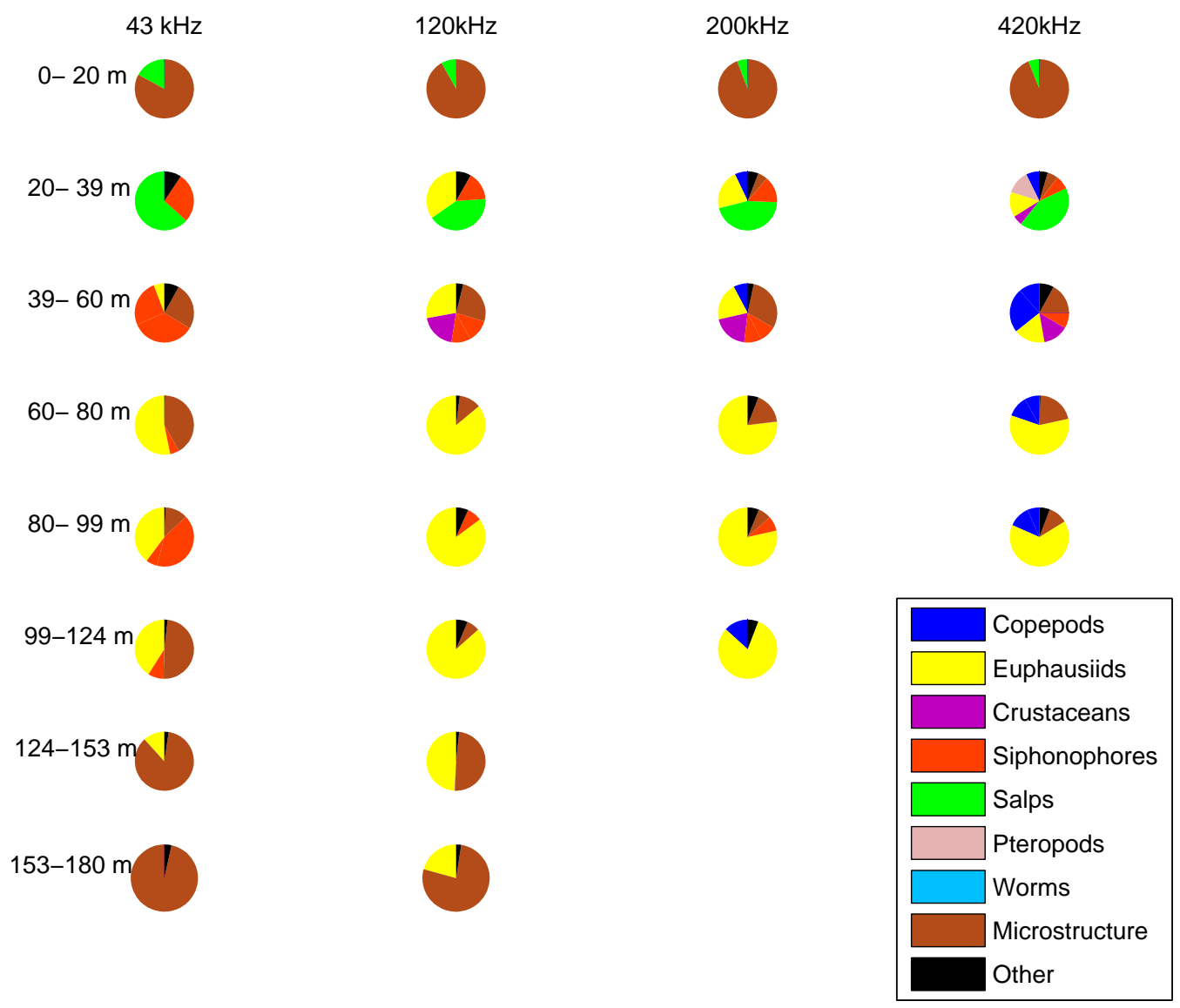

Fig. 7. 


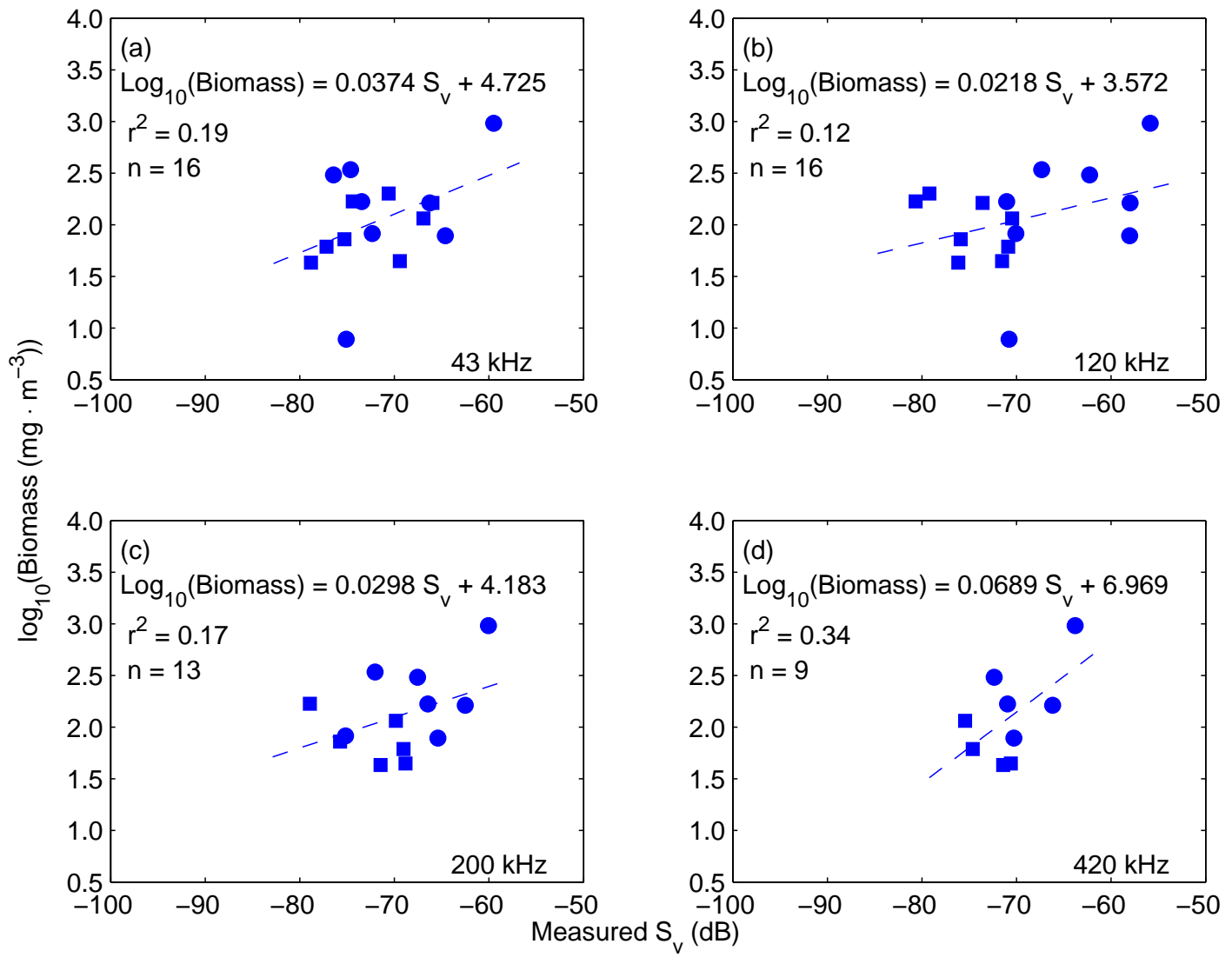

Fig. 8. 


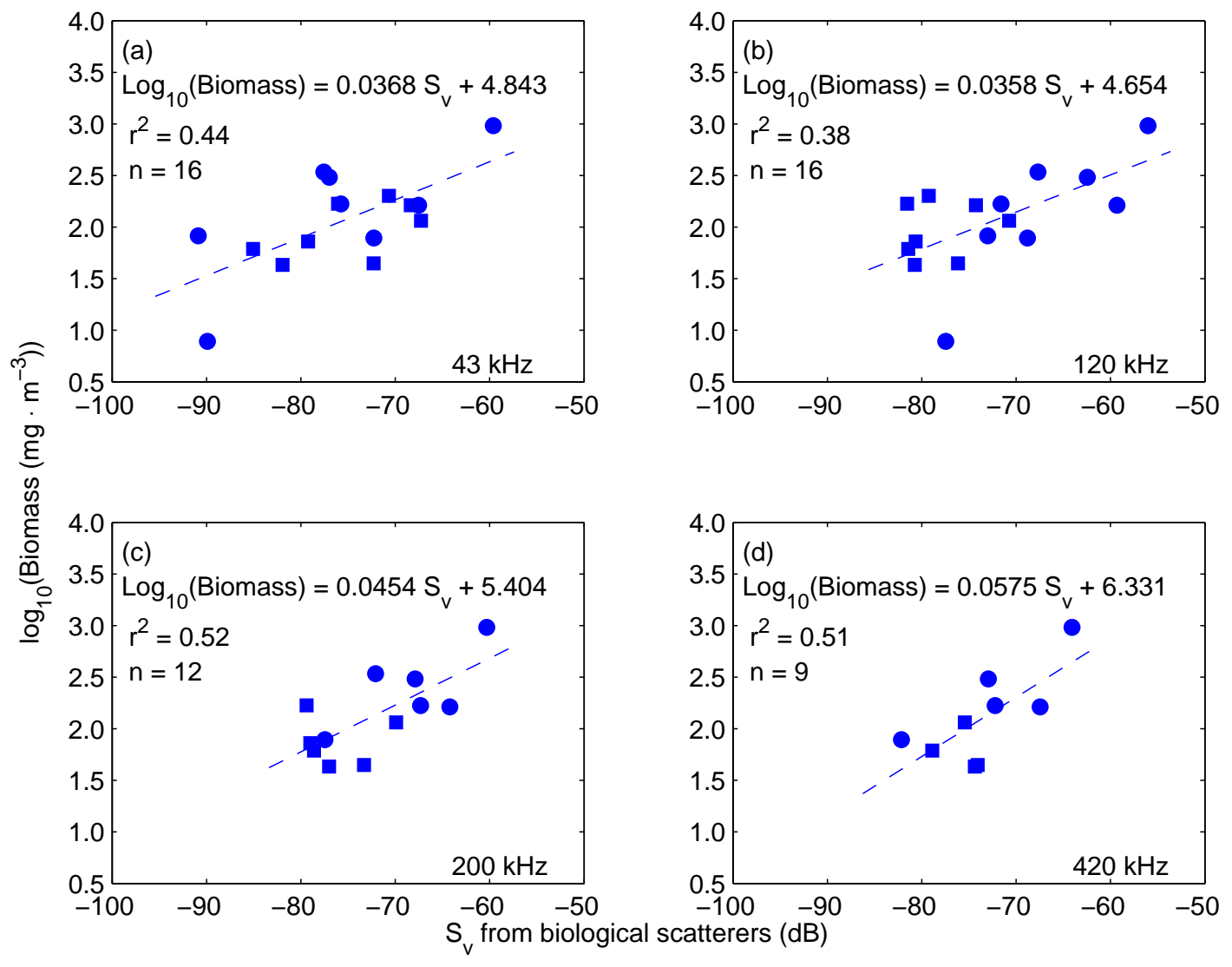

Fig. 9. 